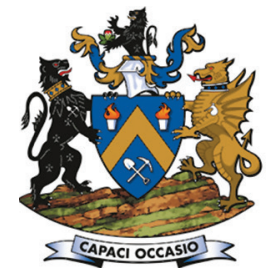

Affiliation:

1 Instituto Tecnológico Vale, Ouro Preto, Brazil.

2 Departamento de Ciência da Computação, Universidade Federal de Minas Gerais, Belo Horizonte, Brazil.

3 Instituto Federal de Minas Gerais, Congonhas, Brazil. ${ }^{4}$ Vale S.A., Nova Lima, Brazil.

5 Instituto Tecnológico Vale, Ouro Preto, Brazil.

Correspondence to:

L.S. Chaves

Email:

leonardo.chaves@itv.org

Dates:

Received: 30 Jun. 2020

Revised: 6 Oct. 2020

Accepted: 6 Oct. 2020

Published: November 2020

\section{How to cite:}

Navarro Torres, V.F., Mateus,

G.R., Martins, A.G., Carneiro, W. and Chaves, L.S. 2020

Integrated optimization and

simulation models for short-term open-pit mine planning.

Journal of the Southern African

Institute of Mining and Metallurgy,

vol. 120 , no. 11 , pp. $617-626$

DOI ID:

http://dx.doi.org/10.17159/2411-

9717/1266/2020

ORCID

V.F. Navarro Torres

https://orchid.org/0000-0002-

4262-0916

G.R. Mateus

https://orchid.org/orcid.org/00000002-7238-0714

A.G. Martins

https://orchid.org/??? 0000-0003-

0698-2300

W. Carneiro

https://orchid.org/0000-0001-

7175-6954

L.S. Chaves

https://orchid.org/0000-00031367-6520

\title{
Integrated optimization and simulation models for short-term open-pit mine planning
}

\author{
V.F. Navarro Torres ${ }^{1}$, G.R. Mateus ${ }^{2}$, A.G. Martins ${ }^{3}$, W. Carneiro ${ }^{4}$, and \\ L.S. Chaves ${ }^{\overline{3}}$
}

\begin{abstract}
Synopsis
Operational mine planning is a fundamental activity in mine operations and should take into account various characteristics of the material, the available mining faces, the requirements of discharge points, and production hiatuses due to reduced equipment operational efficiency, in order to efficiently allocate shovels and trucks and deliver the required tonnage and quality to the proper destinations. This paper presents an approach for optimizing short-term day-to-day mining operations using simulation. A mathematical model based on integer linear programming is developed. The solution is obtained through two different software packages using discrete event simulation (Arena) and a mathematical optimization model (Lingo). The two integrated models search an efficient solution to optimize a set of criteria by applying goal programming to hierarchically optimize five objective functions in a logical priority order under the operator's standpoint and by simulating mining operations and unproductive events to evaluate how closely the optimized results are actually achieved. The integrated models are applied to a real large-scale iron ore mine in southeastern Brazil. A decision support system (DSS) prototype that meets the production requirements is also applied. The results show that an increase in the available loading equipment will not result necessarily in increased production, as expected. The models show satisfactory results and applicability to real and complex mining situations, and the formulation allows for easy adaptation to other mine situations.
\end{abstract}

\section{Keywords}

discrete event simulation, optimization, decision support system, mine planning, linear programming.

\section{Introduction}

Mine planning involves solving complex problems while taking into consideration various parameters and events that may arise through the life of mine. Mining problems such as truck and shovel allocation, ore blending, pit optimization, multi-pit mining, and multiple destinations, etc., are very complex problems that depend on various operational factors, classified as NP-hard problems (Fioroni $e t$ al., 2008; Souza et al., 2010; Thiruvady, Ernst, and Singh, 2014; Patterson, Kozan, and Hyland, 2017; Samavati et al., 2017). In both long- and short-term mine planning, similar problems occur: a mine planner indicates the blocks to be extracted and the mining sequence, respecting quality, production, and any other constraints that may exist, but with different model, constraints, and timespan for each horizon (Blom, Pearce, and Stuckey, 2018). The loading and hauling operations are usually responsible for the highest operating costs in open-pit mining, representing $50-60 \%$ of the total mining operational cost (Ercelebi and Bascetin, 2009; Moradi Afrapoli and Askari-Nasab, 2017; Chaowasakoo et al., 2017; Upadhyay and Askari-Nasab, 2018). The strong relationship between material handling systems and mineral processing plants implies that any delay in material handling causes extra operational costs for the mineral processing plant (Moradi Afrapoli, Tabesh, and Askari-Nasab, 2019). Therefore, the management and allocation of shovels and trucks are fundamental problems that require special attention and efficiency, so that short- and long-term production plans can be executed efficiently.

Truck allocation in mining dispatching systems should take into account the ore quality and the production target required by the processing plant, and should comply with the stripping ratio and other important KPIs provided by the mining plan. Typically, efficiency of truck allocation relies on dispatchers' experience since truck dispatchers usually allocate trucks at the beginning of the shifts, based on past data and user experience (Ta, Ingolfsson, and Doucette, 2013). Short-term and operational planning in open pit mines are recurrent problems solved by different methodologies, including linear programming (LP), mixed integer linear programming (MILP), heuristics and metaheuristics, stochastic optimization, and by applying simulation combined with other mathematical programming techniques. 


\section{Integrated optimization and simulation models for short-term open-pit mine planning}

This paper presents a solution for the short-term mine planning problem through the techniques of optimization and simulation. The solution has some similarity to the simheuristics method, as described by Juan et al. (2015): it solves an NP-hard combinatorial optimization problem by combining a mathematical programming technique with simulation to deal with uncertainty, although it uses an exact model instead of a metaheuristic. The optimization is a MILP model that applies goal programming to hierarchically optimize five objective functions in a logical priority order under operational standpoint. The model also allows for easily modifying the analysed scenarios, equipment, discharge points, and material quantity and characteristics. The outputs are the allocation of loading equipment to the mining units, the number of trips each truck fleet must carry forward, and the destination-origin flows. The discrete event simulation model imports the optimization results and simulates the mining operations in order to fulfil the indicated values by the optimizer, considering the unproductive events that reduce equipment operational efficiency. The unproductive events include maintenance, bad weather, fuel supply, shift changes, and waiting for blasting for both shovels and trucks, and the probability distributions of unavailability events were determined based on experimental samples.

The problem described in this work differs from others in the literature in the complexity of the problem, by managing different objective functions and considering multiple possible destinations, multiple possible material types in the same mining unit, multiple acceptable quality ranges, multiple acceptable particle size ranges, and the mining sequence between units within a mine region. The presented solution can be easily adapted to be applied in other mines with different available equipment, infrastructure, and material types. The models also provide an integrated solution for attending to production requirements simultaneously with minimizing deviations on multiple objectives, and embody an original feature by incorporating particle size requirements, since beneficiation plants have different production circuits based on the particle size ranges, resulting in different products such as lump ore, sinter feed, and pellet feed.

The paper also presents a case study using a database from one of Vale's iron ore mines in southeastern Brazil. Three scenarios were examined, varying the number of items of loading equipment. The site produces material from three pits, each with a different planned stripping ratio, four lithological units, six quality parameters, and six particle size ranges. Quality control is necessary for maintaining a quality balance through the production phase and avoiding production stoppages due to inadequate quality products. In the case study, iron content is controlled by a lower bound while silica, phosphorus, aluminium, and manganese contents are controlled by an upper bound. There are four possible material destinations, including stockpiles, processing plants, and the waste dump. Both processing plants have a homogenization stockpile after the crusher in case production exceeds target or more material is required to achieve the objectives, five types of loading equipment, and four different truck fleets with a total of 34 trucks with different capacities and shovel compatibility.

The problem statement is first presented, followed by an outline of the methodology, descriptions of the optimization and simulation models, and finally the case study and conclusions. A brief literature review on mathematical programming and simulation applications for short-term and operational planning is provided in Appendix A.

\section{Problem statement}

This work deals with short-term, day-to-day mine planning with dynamic allocation of shovels and trucks. The problem consists of selecting mining units for allocating shovels and then allocating truck fleets to these loaders, with the objectives of minimizing deviations in production, quality, and particle size, and maximizing waste extraction and mining rate in areas with more available material. The actual achievement of the optimized results is affected by unplanned downtime for both loading and hauling equipment, which is assessed by discrete event simulation based on practical data provided by the mine dispatch system.

The processing plants are designed to perform in ranges of feed particle size and metal, mineral, and/or contaminant contents, therefore, quality requirements are pre-defined according to the specifications of each processing route, and the same applies to acceptable particle size ranges. The operational planning must consider blending and size requirements, and multiple options of available material in order to allocate shovels and trucks to the mining units and discharge points in a way that maximizes the profit, maintaining the required final product quality. It is still common in the mining industry to encounter 'manual' analysis and decision-taking for production and quality assurance based on visual observations, professional experience, and little available data. In these cases, the solutions are achieved in a trial and error process that may not consider all restrictions and targets simultaneously (Silva Jr., 2019).

It is important to stress that loading and hauling allocation cannot solve the short-term mine planning problem. The main task of truck and shovel operation is material handling, but it also has to comply with quality requirements for ore blending according to the daily extraction plan, which needs to comply with the extraction sequence to deliver the planned quality. Owing to the great structural and quality variability of iron ore deposits located in the Ferriferous Quadrangle Mineral Province, it is crucial at most mines to apply simulation in order to validate the short-term planning and indicate whether the planned objectives are achievable. The simulation may indicate planning problems arising both from equipment utilization and from ore quality in stockpiles and products. Stockpiling is also important in this case, since it contributes to ensuring the production tonnage and quality, providing material with known quality when any other production problem arise or when the active mining faces cannot meet product quality requirements. Therefore, it is also important that the stockpile quality is known and homogeneous.

The mine complex for which this solution is applied is divided into pits, each with its own stripping ratio defined by the mining plan and which may contain one or more mining areas that can be mined independently. Each mining area may comprise more than one mining bench, named according to the area of the mine and the elevation of the working floor of the equipment allocated to this bench. The benches are divided into mining units (MUs), corresponding to the minimum area required to allocate equipment, named with the bench name plus a sequential number to indicate the shovel mining sequence. Mining of the units within a mining bench should respect the order of the MUs (Figure 1). Each unit may contain as many subdivisions as the number of different material types, termed selective mining units (SMUs). The mining order of each SMU must respect the physical order of the mining sequence as the different material types appear in the MU. 


\section{Integrated optimization and simulation models for short-term open-pit mine planning}

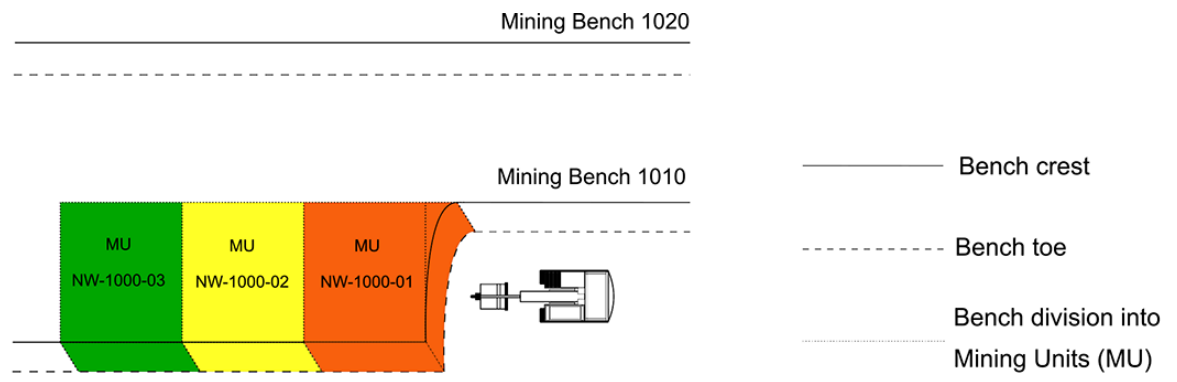

Mining Bench 1000

Figure 1-Schematic of mining in bench 1000 , divided into three sequential MUs

\section{Methodology}

The proposed methodology consists of optimizing the loading and hauling fleet allocation in order to meet production, quality, size, and stripping ratio requirements. A simulation model implemented in Arena software version 14.70.6 informs the optimizer which MUs are available. The optimizer, implemented in Lingo software version 15.0, performs the MILP modelling with the objective of providing the ideal blending between the available MUs to comply with the defined requirements. The combined models are integrated in a software package named Simulavra, which determines the number of trips required for each truck and the allocation of each item of loading and hauling equipment in order to comply with production requirements with minimum deviations in other parameters. The optimizer defines the fleet allocation based on a MU $30 \mathrm{~m}$ wide, $50 \mathrm{~m}$ long, and $10 \mathrm{~m}$ high, resulting in a minimum volume of $15000 \mathrm{~m}^{3}$ for allocating the equipment at an available MU.

The MILP model performs five hierarchical optimizations and returns the number of trips required by each truck fleet to achieve the production targets in each MU and the allocation of the loading equipment. The simulator evaluates whether the fleet can achieve the proposed targets, considering hauling, loading, and dumping times, the intervals between failures, as well as their duration, and the probability of occurrence and duration of the various events affecting production such as maintenance, bad weather, fuel supply, waiting for blasts, or shift changes. Trucks must be directed to loading equipment, and after they are loaded, to discharge points. The decision which loading equipment to allocate the truck to is based on a number of factors, including the number of available items of loading equipment, queue size, compatibility between equipment types, and mining rate. The decision which discharge point the truck should be directed to may vary according to the type of material, availability and capacity of crushers, and compatibility between trucks and unloading points.

The simulator calls the optimizer again if one of the following conditions occurs:

- Completion of $75 \%$ of the scheduled trips

> The simulator remains 60 minutes without any trip of a truck

> The number of trucks waiting for allocation to loading equipment exceeds $60 \%$ of the total number of trucks.

When any of these conditions occurs, the simulator return to the optimizer the part of the MU that could be executed and the optimizer generates a new solution with this new scenario to be simulated. Therefore, communication between the optimizer and the simulator occurs in a cyclic routine during the entire period until an ending condition is encountered. The ending conditions are (i) extraction of the entire planned mass, (ii) end of the simulation period requested, or (iii) all the available MU requires drilling and blasting.

\section{Optimization model}

The problem sets and parameters are presented in Table I and the decision variables are presented in Table II, separated into groups according to their function. The proposed optimization MILP model is composed of five optimization functions in a hierarchical order that prioritize the objectives according to the optimization order by employing the results from the first optimization as constraints to the second, and so on. The first objective function (Equation [1]) prioritizes achieving the planned production target required by longer-term mine plans. The production result enters as constraints for the second optimization function (Equation [2]), which reduces deviations in the total quality limits, accounting for the upper and lower limits of various control variables, such as elements, minerals, or physical/ mechanical properties of the rock. The third objective function (Equation [3]) minimizes the deviations in granulometry size fractions expected by adding the first two solutions (production and quality deviation) as constraints to the model. The fourth function (Equation [4]) maximizes waste extraction in an attempt to keep the stripping ratio close to the planned values. Finally, the fifth objective (Equation [5]) maximizes mining extraction at areas with more available material. Therefore, the proposed model prioritizes multiple objectives in a logical order under the operator's standpoint.

$$
\begin{aligned}
& \operatorname{Min}\left(\sum_{d \in D} \text { eproda }_{d}+\text { eprodb }_{d}\right) \\
& \operatorname{Min}\left(\sum_{d \in D \mid c_{d}=1} \sum_{g \in G} \text { eug }_{d, g}+e l g_{d, g}\right) \\
& \operatorname{Min}\left(\sum_{d \in D \mid c_{d}=1} \sum_{s \in S} e u s_{d, s}+e l s_{d, s}\right) \\
& \operatorname{Max}\left(\sum_{u \in U} \sum_{d \in D} W_{u, d} *\left(1-a t v_{u}\right)\right)
\end{aligned}
$$




\section{Integrated optimization and simulation models for short-term open-pit mine planning}

\section{Table I}

\section{Description of the problem sets and parameters of the model}

\begin{tabular}{|c|c|c|c|}
\hline \multicolumn{4}{|c|}{ Problem sets } \\
\hline D & Set of ore discharge points $d$ (crushers and stockpiles) & $\mathrm{L}$ & Set of loading equipment $I$ \\
\hline $\mathrm{F}$ & Set of MUs $f$ & S & Set of granulometry sizes $s$ \\
\hline G & Set of control variables $g$ & $U$ & Set of SMUs $u$ \\
\hline H & Set of hauling equipment $h$ & & \\
\hline \multicolumn{4}{|c|}{ Problem parameters } \\
\hline pit $_{u}$ & Pit to which u belongs & $\mathrm{cap}_{u}$ & Maximum number of items of loading equipment allowed simultaneously in $u$ \\
\hline $\operatorname{reg}_{u}$ & Region to which $u$ belongs & $\operatorname{amass}_{u}$ & Available mass in $u$ \\
\hline$n b_{u}$ & Mining bench to which $u$ belongs & atvu & If $n$ type $e_{u}$ is ore it equals to 1 , if waste, 0 \\
\hline$n f_{u}$ & Mining unit to which u belongs & ntype $_{u}$ & Material type of $u$ \\
\hline mass_reg $_{u}$ & Total available mass for loading in the region to which $u$ belongs & $c o p_{d}$ & Informs if $d$ is a crusher or a pile \\
\hline mat $_{\text {dntype(u) }}$ & Compatibility between material types in $u$ and $d$ & bench $_{f}$ & Mining bench to which $f$ belongs \\
\hline front $_{f}$ & MU to which $f$ belongs & $a l_{l}$ & Informs if / is available or in maintenance \\
\hline pmax & Maximum productivity for $I$ & pit_comp & Compatibility of each pit with I \\
\hline reg_comp, & Compatibility of mining region with I & ocap $_{h}$ & Ore nominal capacity for trucks from fleet $h$ \\
\hline$w_{c a p}$ & Waste nominal capacity for trucks from fleet $h$ & ctime $_{h}$ & Average cycle time for trucks from fleet $h$ \\
\hline$f n_{h}$ & Number of trucks in fleet $h$ & $y_{d, h, l}$ & Binary matrix that informs if $d$ is compatible with $h$ and $I$ \\
\hline$c g_{u, g}$ & Control grade $g$ of $u$ & part $_{u, g}$ & Partition control grades $g$ of $u$ \\
\hline$u b g_{d, g}$ & Upper bound of control $g$ for discharge $d$ & $\mathrm{lbg}_{d, g}$ & Lower bound of control $g$ for discharge $d$ \\
\hline$u b s_{d, s}$ & Upper bound of control $s$ for discharge $d$ & $l b s_{d, s}$ & Lower bound of control $s$ for discharge $d$ \\
\hline$s z_{u, s}$ & Size distribution $s$ of available material in $u$ & str & Planned stripping ratio \\
\hline time & Total duration of the planned period, in hours & eproda1 $_{d}$ & $\begin{array}{l}\text { Auxiliary variable related to minimum deviations above the production target for } \\
d \text {, obtained in the first optimization }\end{array}$ \\
\hline eprodb $1_{d}$ & $\begin{array}{l}\text { Auxiliary variable related to minimum deviations below } \\
\text { production target for } d \text {, obtained in the first optimization }\end{array}$ & eug1 & $\begin{array}{l}\text { Auxiliary variable related to the minimum sum of deviations of } g \text { to the upper } \\
\text { boundary limits of } d \text {, obtained in the second optimization }\end{array}$ \\
\hline elg1 & $\begin{array}{l}\text { Auxiliary variable related to the minimum sum of deviations of } g \text { to } \\
\text { the lower boundary limits of } d \text {, obtained in the second optimization }\end{array}$ & eus1 & $\begin{array}{l}\text { Auxiliary variable related to the minimum sum of deviations of } s \text { to the upper } \\
\text { boundary limits of } d \text {, obtained in the third optimization }\end{array}$ \\
\hline els1 & $\begin{array}{l}\text { Auxiliary variable related to the minimum sum of deviations of } s \\
\text { to the upper boundary limits of } d \text {, obtained in the third optimization }\end{array}$ & estr1 & $\begin{array}{l}\text { Auxiliary variable related to minimum deviations in waste extraction in relation } \\
\text { to the planned stripping ratio, obtained in the fourth optimization }\end{array}$ \\
\hline
\end{tabular}

\section{Table II}

\section{Description of the decision variables of the model}

\begin{tabular}{|c|c|c|c|}
\hline \multicolumn{4}{|c|}{ Allocation variables } \\
\hline $\begin{array}{l}x_{u, l} \\
x f_{t, l}\end{array}$ & $\begin{array}{l}\text { Binary matrix that informs if } / \text { is allocated in } u \\
\text { Binary matrix that informs if } / \text { is allocated in } f\end{array}$ & $x b_{(f, I)}$ & Binary matrix that informs if $/$ is allocated in $b$ \\
\hline \multicolumn{4}{|c|}{ Number of trips variables } \\
\hline$w_{d, u, h}$ & \multicolumn{3}{|l|}{ Informs the number of cycles required to be performed by $h$ from $u$ to $d$} \\
\hline \multicolumn{4}{|c|}{$\begin{array}{ll} & \text { Mass variables } \\
\end{array}$} \\
\hline$W_{u, d}$ & Mass from $\mathrm{u}$ discharged in $d$ & $W f_{t, d}$ & Mass from $f$ discharged in $d$ \\
\hline \multicolumn{4}{|c|}{ Deviation variables } \\
\hline $\begin{array}{l}\text { eproda }_{d} \\
\text { eug }_{d, g} \\
\text { eus }_{d, s} \\
\text { estr }\end{array}$ & $\begin{array}{l}\text { Deviation above the target production of } d \\
\text { Deviation of control variable } g \text { to upper boundary for discharge } d \\
\text { Deviation of control variable } s \text { to upper boundary for discharge } d \\
\text { Deviation of the waste extraction to meet the planned stripping ratio }\end{array}$ & $\begin{array}{l}e p r o d b_{d} \\
e l g_{d, g} \\
e l s_{d, s} \\
d p r o d_{d}\end{array}$ & $\begin{array}{l}\text { Deviation below the target production of } d \\
\text { Deviation of control variable } g \text { to lower boundary for discharge } d \\
\text { Deviation of control variable } s \text { to lower boundary for discharge } d \\
\text { Target hourly mass production for discharge } d\end{array}$ \\
\hline \multicolumn{4}{|c|}{ Stockpile variables } \\
\hline $\begin{array}{l}\text { plc } c_{d, g} \\
g r l c_{d, s}\end{array}$ & $\begin{array}{l}\text { Partition control grade } g \text { in the stockpile after discharge } d \\
\text { Size distribution } s \text { of material in the stockpile after discharge } d\end{array}$ & $\begin{array}{l}g e c_{d, g} \\
m / c_{d}\end{array}$ & $\begin{array}{l}\text { Control grade values } g \text { in the stockpile after discharge } d \\
\text { Mass stockpiled after discharge } d\end{array}$ \\
\hline
\end{tabular}

$$
\operatorname{Max}\left(\sum_{d \in D} \sum_{j \in J} \sum_{u \in U} \frac{\text { mass_reg }_{u} * W_{u, d}}{1,000,000}\right)
$$

The optimization functions presented are subjected to the following constraints:

$x_{u, l} \leq a l_{l} \quad \forall u \in U$, and $l \in L$ 
$\sum_{l \in L}\left(x_{u, l}\right) \leq \operatorname{cap}_{u} \quad \forall u \in U$

$x_{u, l}=x b_{f, l} \quad \forall u \in U, l \in L$ and $f \in F \mid n b_{u}=x b_{f, l}$

$x_{u, l}=x f_{f, l} \quad \forall u \in U, l \in L$ and $f \in F \mid n f_{u}=x f_{f, l}$

$\sum_{f \in F}\left(x b_{f, l}\right) \leq a l_{l} \quad \forall f \in F, e \forall l \in L$

$\sum_{f \in F}\left(x f_{f, l}\right) \leq a l_{l} \quad \forall f \in F, e \forall l \in L$

$\sum_{d \in D}\left(W f_{f, d}\right) \leq \sum_{l \in L}\left(x b_{f, l} * \operatorname{pmax}_{l} *\right.$ time $) \quad \forall f \in F$

$\sum_{d \in D}\left(W f_{f, d}\right) \leq \sum_{l \in L}\left(x f_{f, l} * \operatorname{pmax}_{l} *\right.$ time $) \quad \forall f \in F$

$\sum_{d \in D}\left(W f_{f, d}\right)=\sum_{u \in U \mid n b_{u}=\text { bench }_{f}}\left[\sum_{d \in D}\left(W_{u, d}\right)\right] \forall f \in F$

$\sum_{d \in D}\left(W f_{f, d}\right)=\sum_{u \in U \mid n f_{u}=\text { front }_{f}}\left[\sum_{d \in D}\left(W_{u, d}\right)\right] \forall f \in F$

$\sum_{d \in d e}\left(W_{u, d}\right) \leq \operatorname{amass}_{u} * \sum_{l \in L}\left(x_{u, l}\right) \quad \forall u \in U$

$W_{u, d}=\sum_{h \in H}\left\{w_{d, u, h} *\left[a t v_{u} * o c a p_{h}+\right.\right.$

$\left.\left.\left(1-a t v_{u}\right) * w c a p_{h}\right]\right\} \quad \forall u \in U$ and $d \in D$

$x_{u, l}=0 \quad \forall l \in L \mid$ pit_comp $p_{l} \neq$

$0, u \in U \mid$ pit $_{u} \neq$ pit_comp $_{l}$

$x_{u, l}=0 \quad \forall l \in L \mid r e g_{-} \operatorname{comp}_{l} \neq$

$0, u \in U \mid r e g_{u} \neq$ reg_comp $p_{l}$

$w_{d, u, h} \leq \sum_{l \in L}\left(y_{d, h, l} * 60 * x_{u, l}\right)$

$\forall d \epsilon D, \forall u \in U$ and $\forall h \in H$

$\sum_{u \in U}\left[\sum_{d \in D}\left(w_{d, u, h}\right)\right] \leq\left[\left(60 \div\right.\right.$ ctime $\left._{h}\right) *$

$f n_{h} *$ time $] \quad \forall h \in H$

eproda $a_{1}-$ eprod $_{1}+$ mlc $_{1}+$

$\sum_{u \in U}\left(W_{u, 1} * a t v_{u}\right)=55,000 \quad \forall d \in D \mid \operatorname{cop}_{d}$

$=1$ or 5 and dprod $_{1} *$ time $>50,000-$ mlc $_{1}$

eproda $a_{2}-$ eprodb $_{2}+$ mlc $_{2}+$

$\sum_{u \in U}\left(W_{u, 2} * a t v_{u}\right)=11,000 \quad \forall d \in D \mid \operatorname{cop}_{d}$

$=1$ or 5 and dprod $2 *$ time $>10,000-m_{l} c_{2}$

eproda $_{1}-$ eprod $_{1}+\sum_{u \in U}\left(W_{u, 1} * a t v_{u}\right)=$

dprod $_{1} *$ time $\forall d \in D \mid \operatorname{cop}_{d}=$

1 or 5 and dprod $_{1} *$ time $<50,000-$ mlc $_{1}$ $\operatorname{eproda}_{2}-\operatorname{eprod}_{2}+\sum_{u \in U}\left(W_{u, 2} * a t v_{u}\right)=$

dprod $_{2} *$ time $\forall d \in D \mid \operatorname{cop}_{d}=$

1 or 5 and dprod $_{2} *$ time $<10,000-$ mlc $_{2}$

$\sum_{u \in U \mid \text { mat }_{\text {dntype }}=0 \text { and ntype }}\left(W_{u, d}\right) \forall d \in D$

$\sum_{u \in U}\left(c g_{u, g} * a t v_{u} * W_{u, d} * \operatorname{part}_{u, g} \div 10000\right)+$

$p l c_{d, g} * g e c_{d, g} * m l c_{d} \div 10000-e u g_{d, g} \leq u b g_{d, g} *$

$\left[p l c_{d, g} * m l c_{d}+\sum_{u \in U}\left(a t v_{u} * W_{u, d} * \operatorname{part}_{u, g}\right)\right] \div$

$10000 \forall d \in D \mid \operatorname{cop}_{d}=1$, and $g \in G \mid u b g_{d, q} \neq 0$

$\sum_{u \in U}\left(c g_{u, g} * a t v_{u} * W_{u, d} * \operatorname{part}_{u, g} \div 10000\right)+$

$p l c_{d, g} * g e c_{d, g} * m l c_{d} \div 10000+e l g_{d, g} \geq l b g_{d, g} *$

$\left[p l c_{d, g} * m l c_{d}+\sum_{u \in U}\left(a t v_{u} * W_{u, d} * \operatorname{part}_{u, g}\right)\right] \div$

$10000 \forall d \in D \mid \operatorname{cop}_{d}=1$, and $g \in G \mid l b g_{d, g} \neq 0$

$\sum_{u \in U}\left(s z_{u, s} * a t v_{u} * W_{u, d} \div 10000\right)+$

$\operatorname{grlc}_{d, g} * m l_{d} \div 10000-e u s_{d, s} \leq u b s_{d, s} *$

$\left[m l c_{d}+\sum_{u \in U}\left(a t v_{u} * W_{u, d}\right)\right] \div 10000$

$\forall d \epsilon D \mid \operatorname{cop}_{d}=1$, and $s \in S \mid u b s_{d, s} \neq 0$

$\sum_{u \in U}\left(s z_{u, s} * a t v_{u} * W_{u, d} \div 10000\right)+$

$\operatorname{grlc}_{d, g} * m l c_{d} \div 10000+e l s_{d, s} \geq l b s_{d, s} *$

$\left[m l c_{d}+\sum_{u \in U}\left(a t v_{u} * W_{u, d}\right)\right] \div 10000$

$\forall d \in D \mid \operatorname{cop}_{d}=1$, and $s \in S \mid l b s_{d, s} \neq 0$

$\sum_{u \in U}\left\{\sum_{d \in D}\left[\left(1-a t v_{u}\right) * W_{u, d}\right]\right\}-\sum_{d \in D}$

$\left[s t r * \sum_{u \in U}\left(a t v_{u} * W_{u, d}\right)\right]+e s t r \geq 0$

$\operatorname{eprodb}_{d} \leq \operatorname{eprodb}_{d}+1 \forall d \epsilon D$

eproda $_{d} \leq$ eproda $_{d}+1 \quad \forall d \epsilon D$

$\sum_{d \in D \mid c o p_{d}=1 \text { or } 5}\left[\sum_{g \in G}\left(e u g_{d, g}\right)\right] \leq e u g 1+1$

$\sum_{d \in D \mid c o p_{d}=1 \text { or } 5}\left[\sum_{g \in G}\left(\operatorname{elg}_{d, g}\right)\right] \leq e \lg 1+1$ 


\section{Integrated optimization and simulation models for short-term open-pit mine planning}

$$
\begin{gathered}
\sum_{d \in D \mid \operatorname{cop}_{d}=1 \text { or } 5}\left[\sum_{g \in G}\left(e s_{d, s}\right)\right] \leq e u s 1+1 \\
\sum_{d \in D \mid c o p_{d}=1 \text { or } 5}\left[\sum_{g \in G}\left(e l s_{d, s}\right)\right] \leq e l s 1+1 \\
\operatorname{estr}=\sum_{u \in U}\left\{\sum_{d \in D}\left[\left(1-a t v_{u}\right) * W_{u, d}\right]\right\} \\
\sum_{u \in U}\left\{\sum_{d \in D}\left[\left(1-a t v_{u}\right) * W_{u, d}\right]\right\}>\operatorname{estr} 1-1
\end{gathered}
$$

The allocation constraints ensure that for each SMU, identified by index $u$, only available loading equipment $(l)$ may be allocated (Equation [6]). The amount of loading equipment allocated to $u$ depends on its capacity (Equation [7]). The equipment allocated to a SMU must be allocated to a mining bench, $x b f, l$ or to a MU, $x f_{f, l}$, to which the SMU belongs (Equations [8] and [9]). The equipment allocated to a bench or to a MU must be available equipment (Equations [10] and [11]). The mass moved in each bench or MU must be less than or equal to the allocated loading equipment's capacity in order to allow for execution within the defined period (Equations [12] and [13]), and must equal the sum of the moved masses in the respective SMUs within this bench (Equations [14] and [15]). The mass moved from each SMU must be lower than or equal to the available mass in that SMU (Equation [16]). The total production for each discharge point must be equal to the total mass moved by all fleets from $u$ to $d$ (Equation [17]). Compatibility constraints ensure the loading equipment must be allocated to a mine or a region that it is compatible with (Equations [18] and [19]). Considering the size of the blocks used in the mine, the total number of fleet trips $h$ from $u$ to $d$ must not exceed 60 (Equation [20]) nor the maximum possible trips calculated using truck cycle times, fleet number of trucks, and planned mining period (Equation [21]). Production constraints ensure minimum production targets are achieved in each crusher (Equations [22] and [23]). The ore production deviations for each crusher are calculated based on the difference between the actual production achieved by each discharge and target values (Equations [24] and [25]). Only compatible material types are sent from $u$ to $d$ (Equation [26]). Quality constraints ensure upper and lower quality limits are respected for each quality control variable $g$ (Equations [27] and [28]). Particle size constraints ensure both upper and lower production target limits for each particle size range are respected (Equations [29] and [30]). The planned stripping ratio must be respected (Equation [31]). Production deviations obtained in each optimization for each $d$ must be lower than or equal to the values obtained by the first hierarchical optimization (Equations [32] and [33]). Similarly, quality mass deviations related to the upper and lower limits must be lower than or equal to the values obtained by the second optimization (Equations [34] and [35]), and particle size deviations related to both upper and lower limits must be lower than or equal to the values obtained by the third optimization (Equations [36] and [37]). Equation [38] defines the total maximized waste extraction obtained in the fourth objective function, and deviations on waste mass for complying with the stripping ratio, obtained by the last optimization should be less than or equal to the result obtained by the fourth optimization solution (Equation [39]).

Each objective function considers several of the presented constraints, but not all of them simultaneously. Function [1] minimizes the production deviations in relation to target production, constrained by the following equations: [6-8], [10], [12], [14], and [16-26]. The second optimization minimizes quality deviations subjected to the following constraints: [6], [7], [9], [11], [13], [15-25], and [27-33]. Function [3] minimizes production deviations of each particle size range, restricted by the same equations of the second optimization plus the constraint Equations [34] and [35]. The fourth objective function maximizes waste extraction restricted to the following constraints: [6], [7], [9], [11], [13], [15-25], [27-30], and [3238]. Finally, the last objective function maximizes mining rate at regions with larger amounts of available mass, constrained by the same equations of the third optimization, plus the constraints of Equations [36], [37], and [39].

\section{Simulation model}

The simulation is conducted by numerical evaluation of discrete events, considering the following factors: (i) interaction between the parts, (ii) dynamics of events occurrence over time, and (iii) randomness of events, providing 'predictability' with respect to the result of a mining plan through the testing of various scenarios to evaluate the effect of planning decisions. The simulation model may be seen as a set of entities that analyse the resources of the system to carry out an activity, subject to both productive and unproductive events. In this work, the entities are the shovel and trucks that will serve the available MU, loading resources, routes, and the unloading resources in order to load and haul the ore and waste to their proper destinations. Each unit operation is described as an element in the simulated system, has a particular operating logic, and is treated independently in the simulation model implemented in the Arena software. Figure 2 provides a schematic diagram for a typical haul cycle in an open pit mine.

The cycle starts with the loading process at the SMU, after which the truck is directed to an unloading point according to the loaded material type, travels to its allocated destination, and discharges. After unloading, the truck is allocated to a loading

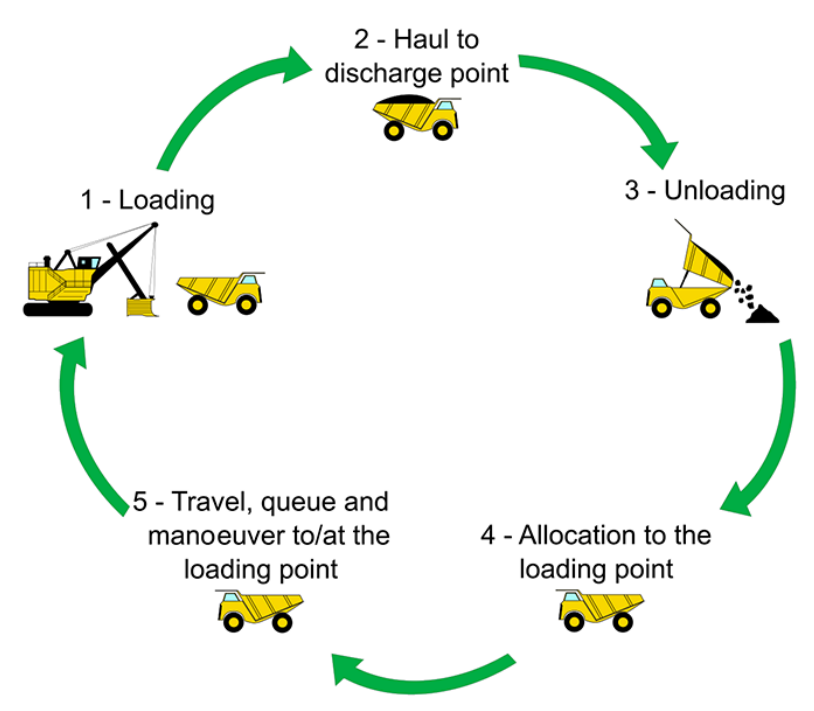

Figure 2-Hauling cycle 


\section{Integrated optimization and simulation models for short-term open-pit mine planning}

point with an available shovel, which is not necessarily the same point as in the previous cycle, travels to the loading point, arrives and queues until the shovel is available for loading this truck, and starts a new cycle. Figure 3 shows the main logical cycle for an item of hauling equipment with its unavailability events, and Figure 4 shows the cycle for loading equipment.

As shown in Figures 3 and 4, both loading and hauling cycles are subjected to the same unavailability events; however, the operational cycle differs and the hauling cycle involves more stages, which were used in the model to evaluate the moment in the cycle each unavailability event occurs, such as truck loading, travelling full, dumping, or travelling empty. The loading cycle is much simpler, since the equipment is relatively fixed in the MUs compared to the hauling equipment. The haul cycle considers that each truck must be instructed which loading equipment it should be directed to in order to be loaded, based on the following factors: number of available items of loading equipment, queue size, compatibility between loading and hauling equipment, and mining rate. The same decision must be made regarding the unloading point, which may vary according to the material type, the availability and capacity of crushers, and compatibility between the trucks and the unloading point. These indicators depend directly on the occurrence of the dynamic and random events, which are site-specific. At the end of the unloading stage, the occurrence of the unavailability events is verified based on the probability distributions of each event's duration and the interval between consecutive events. The unavailability events include the waiting time for a blast, shift changes, supply, bad weather, and maintenance. Waiting for a blast is the time lost while equipment needs to move and stop operation for safety reasons until blasting takes place. Supply is assigned when the truck needs refuelling or any other supply. Bad weather is assigned when weather conditions affect the productivity and safety of employees and equipment, such as heavy rain and fog.

All the events described are random and independent from each other, except the shift changes, which occur regularly, and are represented by probability distributions obtained from historical data in order to account for the frequency of occurrence and the event's duration. Two tables were used to account for the probabilities of duration and intervals between events, one with the date and time of each event assigned by the truck operators and the other with the moment in the truck cycle each event was assigned by the truck operator, such as load, full travel, dump, or empty travel. The availability of each item of equipment is a consequence of equipment breakdowns that require corrective maintenance and of other events such as shift changes, refuelling, bad weather, and waiting for a blast. For each event, two customized probability distributions were generated based on dispatch system information and transformed to continuous distributions in the Arena software, one for the duration of the events and other for the time interval between events.

\section{Case study}

The case study is from a large-scale iron ore mine in southeastern Brazil, using a database of one monthly mining plan. There are three pits, each of which should attempt to comply with a specific stripping ratio, four possible destinations (waste dump, stockpile, and dry and wet processing plants, each with

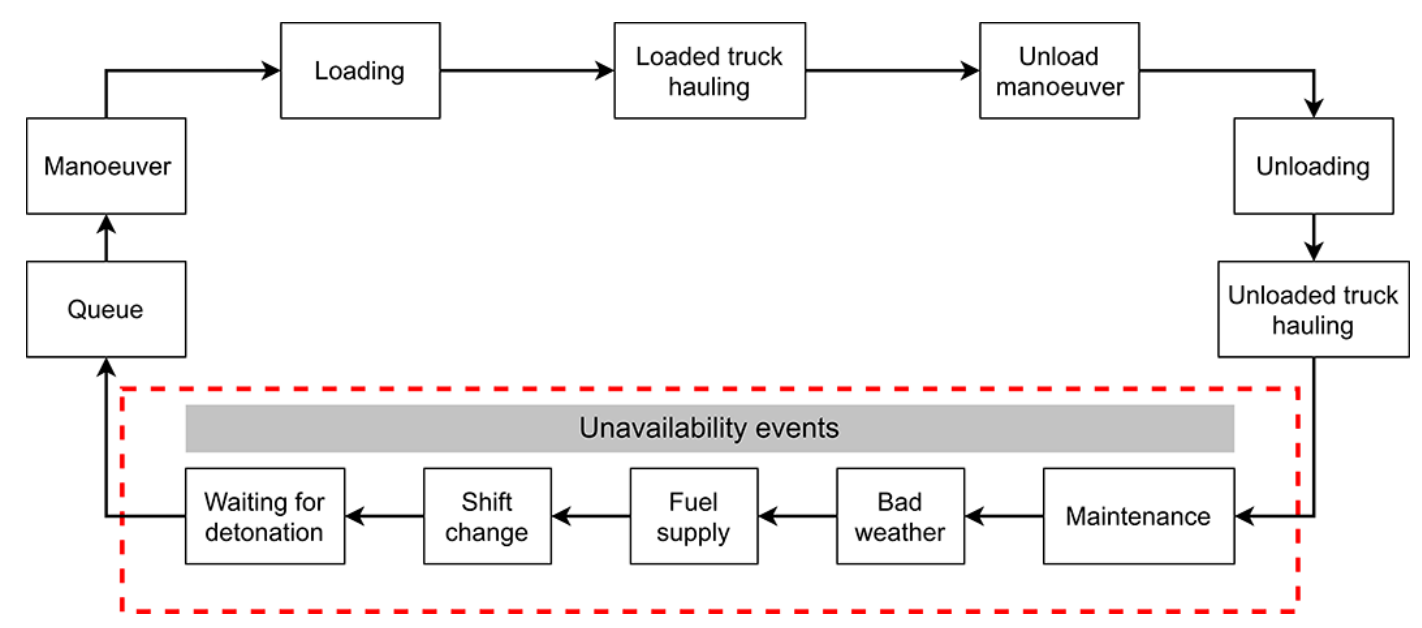

Figure 3-Hauling cycle implemented in the simulation model

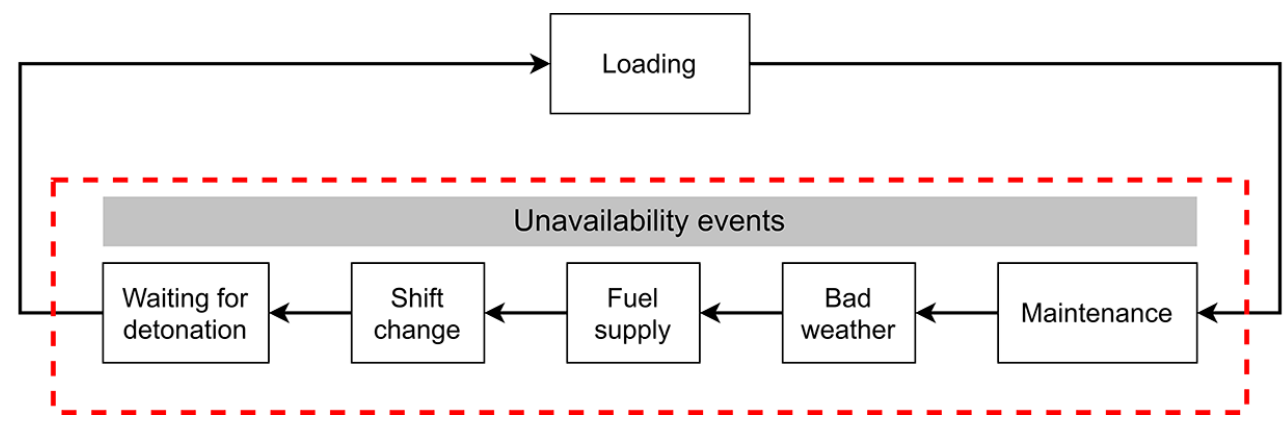

Figure 4-Loading cycle implemented in the simulation model 


\section{Integrated optimization and simulation models for short-term open-pit mine planning}

\section{Table III}

\section{Specification of the loading equipment considered in the simulation}

\begin{tabular}{|l|c|c|c|c|c|}
\hline Loading equipment & Productivity (t/h) & Payload $\left(\mathbf{m}^{\mathbf{3}}\right)$ & Scenario 1 & Scenario 2 & Scenario 3 \\
\hline CAT390 & 457 & 6.0 & 4 & 4 & 3 \\
CAT992 & 626 & 11.0 & 4 & 0 & 3 \\
CAT7295 & 1450 & 19.0 & 1 & 2 & 1 \\
L1350 & 1200 & 19.9 & 2 & 1 & 2 \\
RH170 & 1100 & 1 & 1.0 & 1 \\
\hline
\end{tabular}

\section{Table IV}

\section{Specification of the hauling equipment considered in the simulation}

\begin{tabular}{|l|c|c|c|}
\hline Hauling equipment & Payload $(\mathbf{t})$ & Number & Loading equipment \\
\hline CAT775 & 64 & 13 & CAT992 / CAT390 \\
CAT785 & 135 & 10 & L1350 / RH170 / CAT7295 \\
MT33000 & 135 & 2 & L1350 / RH170 / CAT7295 \\
Scania & 36 & 9 & CAT992 / CAT390 \\
\hline
\end{tabular}

a homogenization stockpile after the crusher) according to the material type (haematite, itabirite, canga, or waste). The material delivered to the destinations is also evaluated according to six quality parameters (iron, silica, phosphorous, aluminium, and manganese contents, and loss on ignition) and six size ranges. The work was carried out considering seven mining regions, five types of loading equipment (Table III), and four different truck fleets, each compatible with specific loading equipment, as described in Table IV.

The ore and waste properties were extracted from the block model and the loading, unloading, manoeuvring, and holding times, as well as the truck speed are real data taken from the mine's dispatch system, to account for the probability distributions of the cycle times, resulting in different distributions for empty trips, loading, full trips, unloading, and spot time. The database used also presents the queue time, which was not considered since it is an output of the simulation. Three scenarios were simulated for this study with differences in the number of items of loading equipment, as detailed by Table III. Scenario 1 considered a full-load fleet, including a CAT7295, a RH170, two L1350s, and four each of the CAT390 and CAT992. Scenario 2 differs from the first in that the CAT7295 is not used, and scenario 3 has one CAT390 and one CAT992 less than scenario 1 . For each scenario, a 29-day period was simulated in order to account for monthly production. The period of 29 days was selected rather than the expected 30 days to allow for the completion of the simulation rounds without exhausting the mining monthly plan. The tests were run on a Windows 10 computer, i7 processor, $2.3 \mathrm{GHz}, 16 \mathrm{~GB}$ of RAM, and it took around 20 minutes to conclude the monthly plan in each scenario, using the presented algorithm with five objective functions, 18 decision variables, and 34 constraints. Figure 5 shows the cumulative ore production and Figure 6 shows the cumulative waste production obtained for the three scenarios.

Both ore and waste production presented an approximate linear behaviour over the 29 days, as expected. However, contrary to what was expected, the reduction in the loading equipment resulted in an increase in ore and waste production. This result led to the conclusion that there is an excess of loading equipment and possibly the removed equipment was allocated far from the destination points, with the long trip between loading and unloading resulting in reduced productivity. Figure 5 shows that ore production decreases close to the end of the period, while Figure 6 shows the opposite behaviour for the waste production, increasing over time. Figure 7 shows the stripping ratio over the simulated period for the extracted and remaining masses.

The decreasing ore and increasing waste production rate result in a successive increase in the remaining stripping ratio, as expected. This leads to the conclusion that most of the ore in the evaluated SMUs was extracted to achieve the production target, and even when including an objective function to maximize waste extraction, most of the remaining material will be waste. The conclusions from this observation highlight the need to include multiple objectives in the optimization model and the high complexity of the problem, showing it is not always possible to comply with multiple requirements simultaneously. It is fundamental to keep to a constant stripping ratio through the life of mine and to respect longer-term mining plans, avoiding

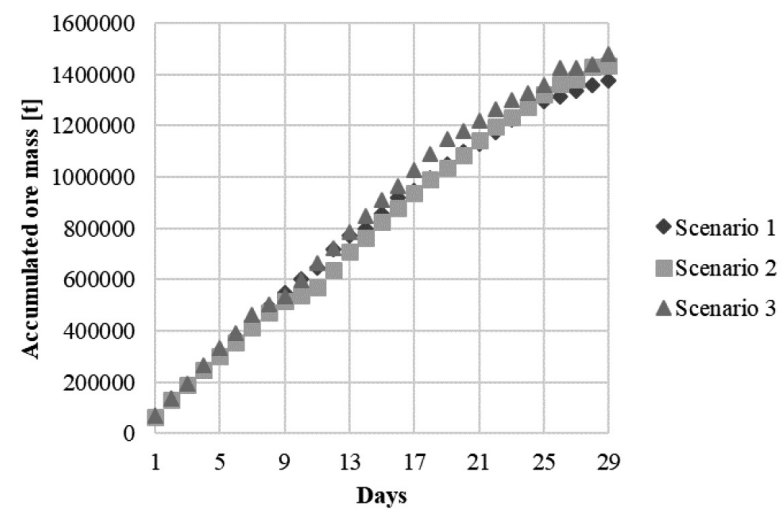

Figure 5-Cumulative ore production over the simulated period for each scenario

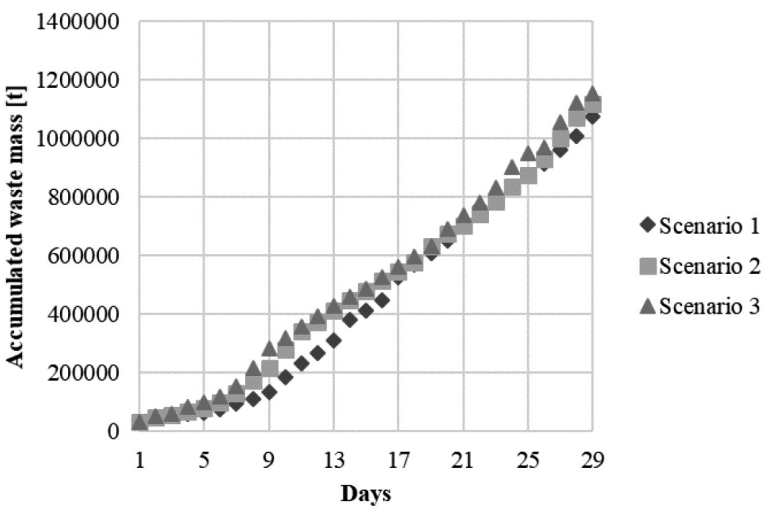

Figure 6-Cumulative waste production over the simulated period for each scenario 


\section{Integrated optimization and simulation models for short-term open-pit mine planning}

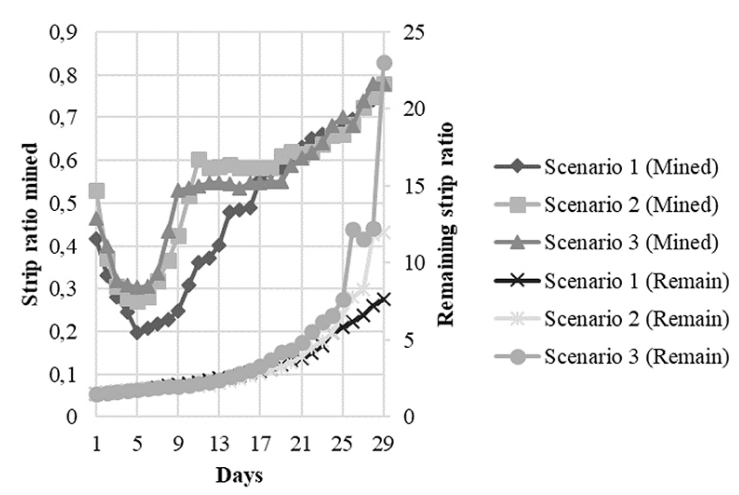

Figure 7-Stripping ratio over the simulated period for the extracted mass (primary vertical axis) and for the remaining mass (secondary vertical axis)

production shortfalls due to unavailability of MUs. In order to evaluate the quality achievements, the global iron content of the ore hauled to each processing plant is presented in Figures 8 and 9 for the dry and wet plants, respectively, including the lower and upper quality targets.

As expected, there is a large variation of the iron content through the simulation period. Such variation is due to a number of factors, including the very restricted monthly mining plan, geological variability of the rock mass, or spatial arrangement of the UMLs not favourable in the short term.

\section{Conclusions}

The integrated methodology presented represents a DSS that demonstrates an important solution to the mine planning and fleet management problems, especially in short-term dayto-day activities. The contributions of the solution include applicability to complex industry problems, as shown by the case study, the possibility of managing different objective functions simultaneously, and easy adaption to other site characteristics.

The results show relatively large variations in the ore quality delivered to the processing plants, which would be expected in such short-term horizons and may be related to the restricted monthly planned production, with limited available mass. The quality variation may affect adherence to and compliance of the indicators. This limitation could possibly be overcome by planning excessive monthly production. In order to make decisions, the ideal scenario would to simulate longer periods than a month in order to further adjust the simulator.

\section{Appendix A}

\section{Literature review}

Mathematical programming and simulation are important techniques in the operational research field with significant applications in the mining industry (Fioroni et al., 2008). Early work in short-term planning of open pit mines was based predominantly on linear programming (Blom, Pearce, and Stuckey, 2018). Chanda and Dagdelen (1995) presented a goaloriented programming model for a coal ore blending problem, considering the economic results for minimizing deviations related to production and quality requirements. Pinto and Merschmann (2001) presented two linear programming models integrated with a simulator in order to allocate loading equipment to the mining faces with the objective of maximizing production, subject to quality and production requirements. Moraes et al.

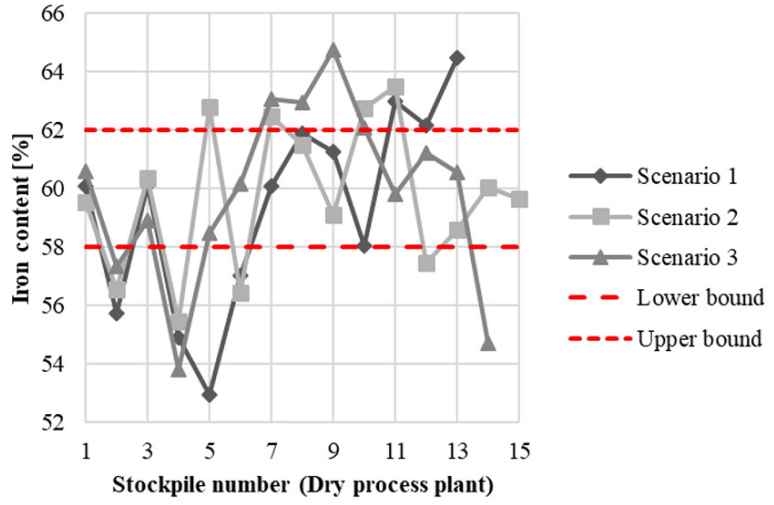

Figure 8-Iron content fed to the dry processing plant for each simulated scenario

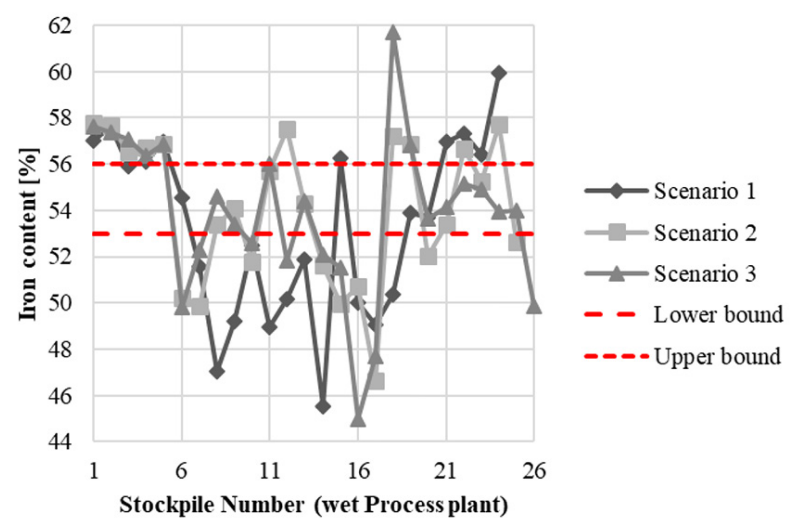

Figure 9-Iron content fed to the wet processing plant for each simulated scenario

(2006) proposed a linear goal-programming model to optimize the composition of the iron ore stockpiled at Vale's Cauê mine in southeastern Brazil.

Talbi (2016) observed that the best results found for many optimization problems in science and industry are obtained by hybrid optimization algorithms, by combining optimization tools and/or machine learning. Souza et al. (2010) presented a hybrid algorithm based on the general variable neighbourhood search technique to deal with operational planning in open pit mining with dynamic truck allocation. The model considered a single discharge point and the objectives were to determine the extraction rate at each pit and minimize the number of trucks required to satisfy both production and quality goals. Samavati et al. (2017) applied the local branching technique combined with a new adaptive branching scheme, and also developed a new heuristic, to find a feasible solution for the open-pit mine production scheduling problem with the objective of determining the block extraction sequence that maximizes the project's net present value.

Integrating simulation and optimization is a common approach that provides a tool for verifying the likeliness of actually achieving an expected result, and the interaction of the simulator with the solver allows robust and near-optimal solutions to be found to complex or stochastic optimization problems (Juan et al., 2015). Camargo et al. (2018) proposed a method of integrated process simulation that supports the development of a decision support system (DSS) considering product quality, process productivity, and production costs to simulate and evaluate the financial impacts of management 


\section{Integrated optimization and simulation models for short-term open-pit mine planning}

decisions along the production chain, production quantities, and product qualities. Juan et al. (2015) describe a general methodology, simheuristics, that allows the extension of metaheuristics through simulation to solve stochastic combinatorial optimization problems as a special case of simulation-optimization approaches, typically optimizationdriven, which can be classified either as an evaluation function or as an analytical model enhancement, depending on its implementation.

Chaowasakoo et al. (2017) proposed a new approach based on differences in the match factor, which is the ratio of the truck arrival rate and the shovel service time, to evaluate and determine ranges for the number of different types of trucks in an optimal fleet considering different scenarios with heterogeneous fleets. Ozdemir and Kumral (2018) proposed an agent-based Petri net simulation model framework to evaluate the performance of material handling systems and the feasibility of the mine plan, observing that the approach can be seen as a risk quantification tool for technical uncertainties. Later, a further step was taken to link the simulation model to the optimization framework for real-time truck dispatching to improve the utilization of mining equipment and production efficiency in a two-stage system. The proposed system increased production by $9.4 \%$ in a shift, compared to the previous dispatching system used in the mine of the presented case study (Ozdemir and Kumral, 2019). Shishvan and Benndorf (2019) proposed a new multi-stage simulation-based optimization approach combining deterministic optimization with stochastic simulation in order to solve a transportation and scheduling problem in a continuous coalmining process. Stochastic optimization is also used for modelling and solving optimization problems under uncertainty. However, much of the recent work in stochastic optimization is related to long-term planning (Blom, Pearce, and Stuckey, 2018).

There are many different approaches described in the literature for solving the truck and shovel allocation problem. Ercelebi and Bascetin (2009) described modelling approaches for truck and shovel operation and optimization, and used closed queuing network theory and LP for dispatching trucks. Ta, Ingolfsson, and Doucette (2013) presented a model for minimizing the number of trucks for a given set of shovels, subjected to production and quality constraints. Patterson, Kozan, and Hyland (2017) proposed a MILP formulation to schedule excavation and haulage activity at an open-pit coal mine with the objective of minimizing energy consumption in shovel and truck operations to meet production targets, considering a heterogeneous equipment fleet, explicit calculation of waiting time, and an energy consumption objective function. Upadhyay and Askari-Nasab (2018) presented an optimization and simulation framework to generate short-term plans within the constraints of the optimal long-term strategic plans, resulting in an uncertainty-based short-term schedule and simulated scenarios for decision-making. Moradi Afrapoli, Tabesh, and Askari-Nasab (2019) developed a multiple objective transportation model for real-time dispatching, attempting to minimize simultaneously the shovel idle times, truck waiting times, and deviations from the path production requirements. Marínquez, González, and Morales (2019) proposed an optimization model based on MILP considering multiple objectives, taking into account the usual restrictions of mine sequencing and both the time and cost for movement between phases of each shovel, by applying hierarchical and weighted sum methods.

\section{References}

Blom, M., Pearce, A.R., and Stuckey, P.J. 2018. Short-term planning for open pit mines: A review. International Journal of Mining, Reclamation and Environment, vol. 33, no. 5. pp. 318-339. doi: 10.1080/17480930.2018.1448248

Camargo, L.F.R., Rodrigues, L.H., Lacerda, D.P., and Piran, F.S. 2018. A method for integrated process simulation in the mining industry. European Journal of Operational Research, vol. 264, no. 3. pp. 1116-1129. doi: 10.1016/j. ejor.2017.07.013

Chanda, E.K.C. And Dagdelen, K. 1995. Optimal blending of mine production using goal programming and interactive graphics systems. International Journal of Surface Mining and Reclamation, vol. 9, no. 4. pp. 203-208. doi: 10.1080/09208119508964748

Chaowasakoo, P., SeppäLÄ, H., KoIvo, H., and Zhou, Q. 2017. Improving fleet management in mines: The benefit of heterogeneous match factor. European Journal of Operational Research, vol. 261, no. 3. pp. 1052-1065. doi: 10.1016/j.ejor.2017.02.039

ERcelebi, S.G., and BAScETin, A. 2009. Optimization of shovel-truck system for surface mining. Journal of the Southern African Institute of Mining and Metallurgy, vol. 109, no. 7. pp. 433-439. http://www.scielo.org.za/scielo.php?script=sci_ arttextandpid=S2225-62532009000700006andlng=enandnrm=iso

Fioroni, M.M., Franzese, L.A.G., Bianchi, T.J., Ezawa, L., Pinto, L.R., and Junior, G.M. 2008. Concurrent simulation and optimization models for mining planning. Proceedings of the 2008 Winter Simulation Conference, Global Gateway. to Discovery - WSC 2008, Miami, FL. pp. 759-767. IEEE, New York. doi: 10.1109/WSC.2008.4736138

Juan, A.A., Faulin, J., Grasman, S.E., Rabe, M., and Figueira, G. 2015. A review of simheuristics: Extending metaheuristics to deal with stochastic combinatorial optimization problems. Operations Research Perspectives, vol. 2. pp. 62-72. doi: 10.1016/j.orp.2015.03.001

Manríquez, F., GonzÁlez, H., and Morales, N. 2019. Short-term open-pit mine production scheduling with hierarchical objectives. Mining Goes Digital: Proceedings of the 39 th International Symposium on Application of Computers and Operations Research in the Mineral Industry (APCOM 2019), Wroclaw, Poland. CRC Press. pp. 443-451.

Moradi Afrapoli, A., and AsKari-NaSAB, H. 2017. Mining fleet management systems: A review of models and algorithms. International Journal of Mining, Reclamation and Environment, vol. 33, no. 1. pp. 42-60. doi: 10.1080/17480930.2017.1336607

Moradi Afrapoli, A., TAbesh, M., and Askari-Nasab, H. 2019. A multiple objective transportation problem approach to dynamic truck dispatching in surface mines. European Journal of Operational Research, vol. 276, no. 1. pp. 331-342. doi: 10.1016/j.ejor.2019.01.008

Moraes, E.F., Alves, J.M.C.B., Souza, M.J.F., Cabral, I.E., and Martins, A.X. 2006. Um modelo de programação matemática para otimizar a composição de lotes de minério de ferro da mina Cauê da CVRD. REM: Revista Escola de Minas, vol. 59, no. 3. pp. 299-306. doi: 10.1590/s0370-44672006000300008

Ozdemir, B. and KumRAL, M. 2018. Appraising production targets through agentbased Petri net simulation of material handling systems in open pit mines. Simulation Modelling Practice and Theory, vol. 87. pp. 138-154. doi: 10.1016/j.simpat.2018.06.008

OzDEmiR, B. and KumRAL, M. 2019. Simulation-based optimization of truck-shovel material handling systems in multi-pit surface mines. Simulation Modelling Practice and Theory, vol. 95. pp. 36-48. doi: 10.1016/j.simpat.2019.04.006

PatTerson, S.R., KozAn, E., and HyLand, P. 2017. Energy efficient scheduling of openpit coal mine trucks. European Journal of Operational Research, vol. 262, no. 2 pp. 759-770. doi: 10.1016/j.ejor.2017.03.081

Pinto, L.R. and Merschmann, L.H.C. 2001. Planejamento operacional de lavra de mina usando modelos matemáticos. REM: Revista Escola de Minas, vol. 54, no. 3. pp. 211-214. doi: 10.1590/S0370-44672001000300008

Samavati, M., Essam, D., Nehring, M., and SARKer, R. 2017. A local branching heuristic for the open pit mine production scheduling problem. European Journal of Operational Research, vol. 257, no. 1. pp. 261-271. doi: 10.1016/j. ejor.2016.07.004

SHISHVAN, M.S. and BENNDoRF, J. 2019. Simulation-based optimization approach for material dispatching in continuous mining systems. European Journal of Operational Research, vol. 275, no. 3. pp. 1108-1125. doi: 10.1016/j. ejor.2018.12.015

SILVA JR., A.L. 2019. Planejamento operacional de lavra: desenvolvimento de um modelo matemático para as minas de Capão Xavier e Mar Azul. Master's thesis, Programa de Pós-Graduação em Instrumentação, Controle e Automação de Processos de Mineração (PROFICAM), Universidade Federal de Ouro Preto and Associação Instituto Tecnológico Vale. https://www.repositorio.ufop.br/ handle/123456789/11777

Souza, M.J.F., Coelho, I.M., Ribas, S., Santos, H.G., and Merschmann, L.H.C. 2010. A hybrid heuristic algorithm for the open-pit-mining operational planning problem. European Journal of Operational Research, vol. 207, no. 2. pp. 1041-1051. doi: 10.1016/j.ejor.2010.05.031

TA, C.H., Ingolfsson, A., and DoucetTe, J. 2013. A linear model for surface mining haul truck allocation incorporating shovel idle probabilities. European Journal of Operational Research, vol. 231, no. 3. pp. 770-778. doi: 10.1016/j. ejor.2013.06.016

TALBI, E. 2016. Combining metaheuristics with mathematical programming, constraint programming and machine learning. Annals of Operations Research, vol. 240, no. 1. pp. 171-215. doi: 10.1007/s10479-015-2034-y

Thiruvady, D., ERnst, A.T., and Singh, G. 2014. Parallel ant colony optimization for resource constrained job scheduling. Annals of Operations Research, vol. 242, no. 2. pp. 355-372. doi: 10.1007/s10479-014-1577-7

UpADHYAY, S.P., and AsKaRi-NASABI, H. 2018. Simulation and optimization approach for uncertainty-based short-term planning in open pit mines. International Journal of Mining Science and Technology, vol. 28, no. 2. pp. 153-166. doi: 10.1016/j.ijmst.2017.12.003 